\title{
Gaps between the subjective needs of older facility residents and how care workers understand them: a pairwise cross-sectional study
}

\author{
Tomoko Ohura ${ }^{1,2^{*}}$, Takahiro Higashi ${ }^{3}$, Tatsuro Ishizaki ${ }^{4}$ and Takeo Nakayama ${ }^{1}$
}

\begin{abstract}
Background: To promote active daily living and improve the quality of life of older facility residents, it is important that care staff understand their day-to-day activities and needs. However, only a few studies have examined the needs of older residents and how care workers understand them. This study aimed to examine the subjective needs of older residents at aged care facilities, care workers' understanding of these needs, and the gaps that exist between them.

Methods: Structured interviews with older residents with no severe cognitive impairment in ten Japanese aged care facilities and a questionnaire survey of care workers were conducted in 2008 regarding resident subjective needs. The questionnaire, which had satisfactory factorial validity, internal consistency, and reproducibility, consisted of seven items on basic activities of daily living (BADL), five items on instrumental $A D L(I A D L)$, eight items on environment and lifestyle (EL), and five items on emotion (EM). Pair-wise analyses were performed to compare responses.

Results: Responses of 115 pairs were analyzed (residents $\geq 75$ years, $85 \%$; 21 men, 94 women). Median proportions of residents with IADL (66\%) and EL (69\%) needs were lower compared with those with BADL (83\%) and EM (91 \%) needs. Median proportions of care workers understanding IADL (55\%) and EL (60 \%) needs were lower compared with those understanding BADL (87 \%) and EM (87\%) needs. Less than half of the care workers understood IADL needs for household chores (30 \%) and money management (43\%), and an EL need for playing a role (41 \%).

Conclusions: Gaps were found between resident subjective needs and how care workers understood them. Specifically, care workers underestimated older residents' IADL and EL needs, especially with regard to playing a role. These results highlight the need for care workers to set goals based on each resident's subjective needs and plan strategies for care provision accordingly.
\end{abstract}

Keywords: Care for older people, Subjective needs, Older facility residents, Care workers

\section{Background}

Recent years have seen a rapid increase in aging populations in developed countries [1]. Among them, Japan has the highest proportion of people aged 60 years or older in the world (32\% in 2013) [2]. Various studies, ranging from biomedical aspects to psychology and social

\footnotetext{
*Correspondence: oh-ura@umin.ac.jp

1 Department of Health Informatics, Kyoto University School of Public

Health, Yoshida Konoe-cho, Sakyo-ku, Kyoto 606-8501, Japan

Full list of author information is available at the end of the article
}

science-related themes, have been conducted on aging [3].

The Japanese government instituted a universal longterm insurance system in 2000 [4]. The initial number of facility service users was 520,000 , but this expanded to 890,000 in 2013 [5]. Various types of facilities covered by long-term care insurance for older people exist in Japan, including special nursing homes, health service facilities, and sanatorium-type medical care facilities. Special nursing homes provide regular nursing care, and sanatoriumtype medical care facilities provide medical services and 
care. Health service facilities, which are similar to geriatric intermediate care facilities, provide rehabilitation and care, and support discharge to home.

The quality of long-term care can be evaluated from medical and technical perspectives, as well as a care receiver's sense of satisfaction [6]. When considering care quality, comprehensive and efficient measures of care quality for older people have been developed [7], and some studies have advocated that care providers should understand the individual needs of those they care for $[8$, 9]. To better understand the subjective needs of aged care facility residents, a 25 -item instrument for care providers to assess older people's needs [10] was developed based on an interview study [11]. This instrument showed satisfactory factorial validity, internal consistency, and reproducibility in the context of assessing the subjective needs of institutionalized older people [10].

To improve active daily living and quality of life (QOL) of older facility residents, it is paramount that care staff understand their day-to-day activities and needs. This study aimed to examine the subjective needs of older residents at aged care facilities, care worker's understanding of these needs, and gaps that exist between them.

\section{Methods}

We conducted a pairwise cross-sectional study using a 25 -item questionnaire [10] to measure both the subjective needs of older facility residents and care workers' understanding of residents' needs.

\section{Questionnaire}

We evaluated the activities that residents wished to perform using a 25-item questionnaire [10], which was developed based on semi-structured interviews with care providers regarding care goals (2006) [11] and consideration of previous studies $[12,13]$. The questionnaire encompassed the following four areas: basic activities of daily living (BADL), instrumental activities of daily living (IADL), environment and lifestyle (EL), and emotion (EM). Questions were asked in terms of "whether you want to perform each behavior regardless of the need for assistance," rather than "whether you want assistance or not when attempting each behavior". Residents were asked to grade each item using a five-point Likert scale (5: "strongly agree", 4: "agree", 3: "neutral", 2: "disagree", 1: "strongly disagree") (Additional file 1). The questionnaire was validated using data collected in this study $(\mathrm{n}=120$, $\chi^{2} / \mathrm{df}=1.090$, RMSEA $=0.03$; all standardized path coefficients ranged from 0.28 to 0.87 ), and was determined to be reproducible using data collected in 2011 ( $\mathrm{n}=18 ; 14$ of 25 items showed weighted kappa coefficients $\geq 0.60$ ) [10]. This questionnaire [10] was also used to assess how care workers understood the needs of each resident (Additional file 2).

\section{Participants and study setting}

We conducted interviews with older residents of 10 facilities in Kyoto, Shiga, and Ishikawa Prefectures (two special nursing homes and eight health services facilities) (January-March 2008). A questionnaire survey was conducted with attending physicians, care managers, nurses, care workers, and rehabilitation staff (physical therapist, occupational therapist, and speech-language therapist). In this study, we only used responses from care workers who could be paired with older residents. Only older residents who were able to verbally communicate were selected arbitrarily by facility staff for this study. With respect to cognitive function, those with a Mini Mental State Examination [14] score $\leq 17$ points (severe cognitive impairment) were excluded. Of the 129 older residents who provided consent to participate in the study, six were either discharged or withdrew their consent during the study period. Of the remaining 123 older residents, 119 for whom two care workers could be assigned to complete the questionnaires were included as participants of this study (Fig. 1). With respect to the background of the 10 facilities where the 119 older participants resided, the number of residents at each facility ranged from 84 to 240 (total, 1195 residents) at the time of the survey. The occupancy rate of each facility was between 90 and $100 \%$, and the number of study participants at each facility (6 to 29 residents) accounted for between 4 and $14 \%$ of the total older residents.

\section{Data collection}

We conducted a pilot study at two facilities before this study in order to verify the procedures. The questionnaires completed by care workers were kept in individual envelopes and collected by responsible personnel at each facility. We visited each facility to collect the questionnaires 6-8 days after distribution. We then performed individual interviews to ask each participant questions on the questionnaire form; this process reflects our effort to address potential sources of information bias for healthcare staff. If any participants were discharged from the facility, we excluded their data as well as the matched questionnaires completed by their care workers. Interviews were conducted by four healthcare professionals (one occupational therapist and three nurses) using standardized methods. Basic information including gender, age, duration of residence, Mini Mental State Examination [14], and activities of daily living (ADL) [15] was obtained from the resident records and facility staff. 


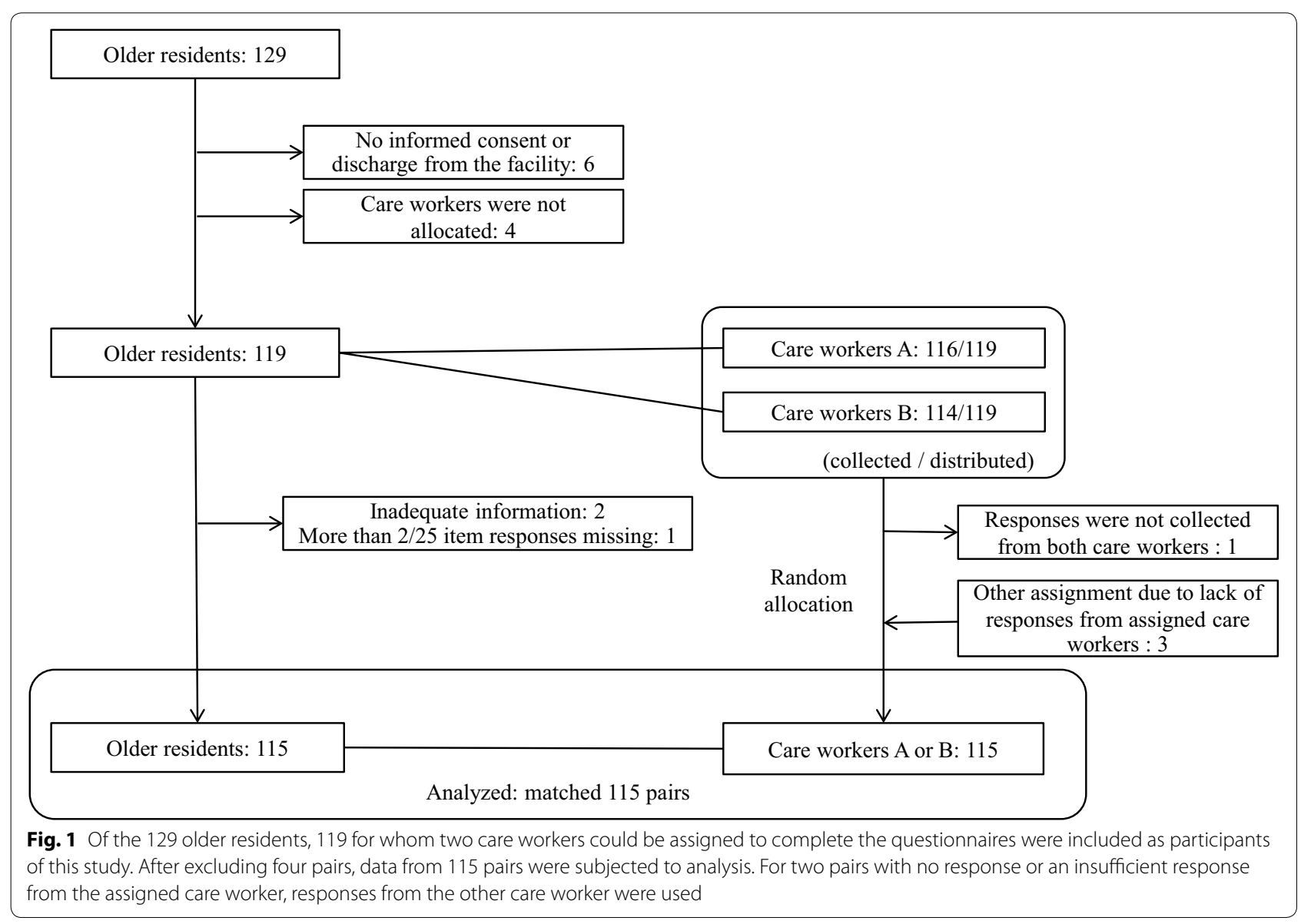

Older participants were given gifts worth about 500 yen (about 4.8 USD/3.5 EUR at the time of writing), and facilities were given bookstore gift certificates according to the number of times they participated in the survey.

\section{Statistical analysis}

We matched each older resident with two care workers who engaged in his/her care, and both care workers responded to a questionnaire regarding the resident.

We excluded pairs that provided insufficient responses to the questionnaire (i.e., two or more missing responses to the 25-item questionnaire or missing information regarding resident characteristics). If the care worker who was randomly selected out of the two assigned for each older resident did not respond to the questionnaire or had two or more missing responses, responses from the other care worker were used. Pairs for which none of the assigned care workers provided sufficient responses were excluded from the analyses.

Resident and care worker responses regarding subjective needs were evaluated on a five-point scale, and were each aggregated into two categories (4-5: with subjective needs; 1-3: without subjective needs and neutral). The proportion of residents with subjective needs and the proportion of care workers who understood the resident needs were shown along with $95 \%$ confidence intervals (CIs) [16] for each questionnaire item.

As an additional statistical analysis, the Chi square test was performed to analyze the relationships between basic attributes and the presence or absence of resident needs, and the number of questionnaire forms completed by care workers and their basic attributes, with $\mathrm{p}<0.05$ set as a statistically significant level [17]. Furthermore, to account for multiple comparisons, the Bonferroni correction [17] was used. These analyses were performed using IBM SPSS Statistics 20 [18].

\section{Ethical procedure}

The study protocol was approved by the Ethics Committee of Kyoto University Graduate School and Faculty of Medicine (E347). Although not all participating facilities had an ethics committee, the director of each facility approved the study, and notices of the study were posted at all facilities. The study objective was explained to the participants and/or their families, and written consent was obtained. All participating care workers were given 
written information, and completed questionnaires were considered their consent to participate. All collected data were subjected to linkable anonymization, and personally identifiable information, such as subject name, was never taken outside the facilities.

\section{Results}

Data from 115 pairs were subjected to analysis. For two pairs with no response or an insufficient response from the assigned care worker, responses from the other care worker were used (Fig. 1). Resident and care worker characteristics are summarized in Tables 1 and 2. Of the 115 participants, 94 (82\%) were female, 98 (85\%) were aged 75 years or older, and $82(71 \%)$ were residents for 6 months and longer. The levels of independence were as follows: $77(67 \%)$ maintained mobility (either ambulation or wheelchair), 68 (59\%) were able to transfer to a chair or bed alone, and 56 (49\%) were able to use the lavatory (Table 1). Questionnaire forms for each of the 115 residents were filled out by 78 care workers. Of these, 49 (63\%) were female, 37 (47\%) were aged $20-29$ years, and $34(44 \%)$ had fewer than 5 years of work experience (Table 2).

Table 1 Characteristics of older residents

\begin{tabular}{|c|c|c|}
\hline & \multicolumn{2}{|l|}{ Resident } \\
\hline & $N=115$ & (\%) \\
\hline \multicolumn{3}{|l|}{ Gender } \\
\hline Female & 94 & $(82)$ \\
\hline Male & 21 & (18) \\
\hline \multicolumn{3}{|l|}{ Type of facility } \\
\hline $\mathrm{NH}$ & 15 & (13) \\
\hline GICF & 100 & $(87)$ \\
\hline \multicolumn{3}{|l|}{ Age } \\
\hline$<75$ years & 17 & (15) \\
\hline$\geq 75$ years & 98 & $(85)$ \\
\hline \multicolumn{3}{|l|}{ Length of stay } \\
\hline$<6$ months & 33 & $(29)$ \\
\hline$\geq 6$ months & 82 & (71) \\
\hline \multicolumn{3}{|l|}{ Independence in $\mathrm{ADL}$} \\
\hline Moving: walking & 44 & (38) \\
\hline Moving: w/c & 33 & (29) \\
\hline Transfer & 68 & (59) \\
\hline Using the lavatory $(N=113)$ & 56 & $(49)$ \\
\hline Eating & 77 & $(67)$ \\
\hline Changing clothes & 55 & $(48)$ \\
\hline \multicolumn{3}{|l|}{ MMSE } \\
\hline$\geq 24$ & 60 & $(52)$ \\
\hline $23-18$ & 55 & (48) \\
\hline
\end{tabular}

GICF geriatric intermediate care facility, $N H$ nursing home, W/C wheelchair, $A D L$ activities of daily living, MMSE mini mental state examination
Table 2 Characteristics of care workers

\begin{tabular}{|c|c|c|}
\hline & \multicolumn{2}{|c|}{ Care worker } \\
\hline & $\mathrm{N}=78$ & (\%) \\
\hline \multicolumn{3}{|l|}{ Gender } \\
\hline Female & 49 & $(63)$ \\
\hline Male & 29 & $(37)$ \\
\hline \multicolumn{3}{|l|}{ Age } \\
\hline $20-29$ years & 37 & $(47)$ \\
\hline $30-49$ years & 31 & $(40)$ \\
\hline$\geq 50$ years & 10 & (13) \\
\hline \multicolumn{3}{|c|}{ Length of work } \\
\hline$<5$ years & 34 & (44) \\
\hline $5-9$ years & 25 & (32) \\
\hline$\geq 10$ years & 12 & $(15)$ \\
\hline Unknown & 7 & (9) \\
\hline \multicolumn{3}{|c|}{ Length of work at the facility } \\
\hline$<5$ years & 36 & (46) \\
\hline $5-9$ years & 24 & (31) \\
\hline$\geq 10$ years & 6 & (8) \\
\hline Unknown & 12 & (15) \\
\hline \multicolumn{3}{|c|}{ Number of questionnaires for analysis } \\
\hline One & 52 & $(67)$ \\
\hline Two & 19 & $(24)$ \\
\hline Three & 4 & (5) \\
\hline Four & 2 & (3) \\
\hline Five & 1 & (1) \\
\hline
\end{tabular}

No significant differences were found in basic characteristics (age, gender, and years of experience) of care workers by the number of older residents assessed

Table 3 shows resident responses to each questionnaire item. With regard to resident subjective needs, median proportion (minimum-maximum) was $83 \%$ (71-94\%) for BADL needs and $91 \%$ (87-92 \%) for EM needs. In contrast, median proportion was $66 \%$ (55-69 \%) for IADL needs and $69 \%$ (25-81 \%) for EL needs. Only one item (Q19) in the areas of IADL and EL had a proportion higher than $80 \%$ (81\%), and only one of the 25 items (Q15) had a proportion lower than 50 \% (25\%) (Table 4).

As shown in Table 3, care workers were less likely to understand resident needs in IADL and EL areas than in BADL and EM areas [IADL; $55 \%$ (30-67\%), EL; $60 \%$ (41-84 \%), BADL; $87 \%$ (61-97 \%), EM; $87 \%$ (77-92\%)]. Care workers poorly understood resident needs for IADL [Q11: keeping money at hand (43\%), Q12: performing household chores themselves (30\%)], and a need for EL [Q18: playing a role (41 \%)] (Table 4).

The additional analysis revealed no significant difference in the proportions of residents with subjective needs by gender, age, cognitive function level, level of care needed, and independence in other ADL. Moreover, no significant difference was found in basic characteristics 
Table 3 Median proportion of resident subjective needs and resident needs understood by care workers in each area

\begin{tabular}{llll}
\hline & Items & $\begin{array}{l}\text { Resident subjective needs } \\
\% \text { (minimum-maximum) }\end{array}$ & $\begin{array}{l}\text { Resident needs understood by care workers } \\
\% \text { (minimum-maximum) }\end{array}$ \\
\hline BADL & 7 & $83(71-94)$ & $87(61-97)$ \\
IADL & 5 & $66(55-69)$ & $55(30-67)$ \\
EL & 8 & $69(25-81)$ & $60(41-84)$ \\
EM & 5 & $91(87-92)$ & $87(77-92)$ \\
\hline
\end{tabular}

$B A D L$ basic activities of daily living, $I A D L$ instrumental activities of daily living, $E L$ environment and lifestyle, $E M$ emotion

Table 4 Proportion of resident subjective needs and resident needs understood by care workers

\begin{tabular}{|c|c|c|c|c|c|c|c|}
\hline & & & \multicolumn{3}{|c|}{$\begin{array}{l}\text { Resident subjective } \\
\text { needs }\end{array}$} & \multicolumn{2}{|c|}{$\begin{array}{l}\text { Resident needs } \\
\text { understood } \\
\text { by care workers }\end{array}$} \\
\hline & & & All & N1 & $(\%, 95 \% \mathrm{Cl})$ & N2 & $(\%, 95 \% \mathrm{Cl})$ \\
\hline BADL & Q1 & Go to the toilet when one wants to (includes both independently or with help) & 115 & 108 & $(94,88-97)$ & 98 & $(91,84-95)$ \\
\hline EM & Q25 & Desire to live without worry (e.g., health, food, clothing, shelter, living, and relationships) & 114 & 105 & $(92,86-96)$ & 96 & $(91,85-95)$ \\
\hline EM & Q21 & Desire to live without worrying about health & 115 & 105 & $(91,85-95)$ & 97 & $(92,86-96)$ \\
\hline EM & Q23 & Desire to live feeling good without getting depressed & 115 & 105 & $(91,85-95)$ & 91 & $(87,79-92)$ \\
\hline EM & Q24 & Desire to live enjoyable days & 115 & 101 & $(88,81-93)$ & 88 & $(87,79-92)$ \\
\hline EM & Q22 & Desire to be free of bodily pain & 115 & 100 & $(87,80-92)$ & 77 & $(77,68-84)$ \\
\hline BADL & Q4 & Desire to change clothes at one's own pace (includes both independently and with help) & 114 & 97 & $(85,77-90)$ & 84 & $(87,78-92)$ \\
\hline BADL & Q3 & Desire to eat at one's own pace (includes both independently and with help) & 114 & 95 & $(83,75-89)$ & 85 & $(89,82-94)$ \\
\hline BADL & Q5 & $\begin{array}{l}\text { Desire to brush teeth (includes washing dentures) when one wants to (includes both inde- } \\
\text { pendently and with help) }\end{array}$ & 115 & 95 & $(83,75-88)$ & 78 & $(82,73-89)$ \\
\hline EL & Q19 & Desire to move around for health & 115 & 93 & $(81,73-87)$ & 53 & $(57,47-67)$ \\
\hline BADL & Q2 & Take a bath when one wants to (includes both independently or with help) & 115 & 91 & $(79,71-86)$ & 65 & $(71,61-80)$ \\
\hline BADL & Q6 & $\begin{array}{l}\text { Desire to move around the facility when one wants to (includes both independently and with } \\
\text { help) }\end{array}$ & 115 & 89 & $(77,69-84)$ & 86 & $(97,91-99)$ \\
\hline EL & Q17 & Desire to carry out one's preferred hobbies (e.g., reading, sports, games) & 115 & 86 & $(75,66-82)$ & 55 & $(64,53-73)$ \\
\hline BADL & Q7 & $\begin{array}{l}\text { Desire to go outside the facility when one wants to (includes both independently and with } \\
\text { help) }\end{array}$ & 115 & 82 & $(71,62-79)$ & 50 & $(61,50-71)$ \\
\hline EL & Q14 & Desire to talk with family or people other than staff & 115 & 81 & $(70,62-78)$ & 68 & $(84,74-90)$ \\
\hline EL & Q20 & Desire to go out to any location when one wants to (e.g., taking a walk, shopping, leisure) & 115 & 81 & $(70,62-78)$ & 50 & $(62,51-72)$ \\
\hline IADL & Q10 & $\begin{array}{l}\text { Desire to interact by phone or letters when one wants to (includes both independently and } \\
\text { with help) }\end{array}$ & 115 & 79 & $(69,60-76)$ & 53 & $(67,56-76)$ \\
\hline EL & Q18 & Desire to carry out activities that give one a role in the facility, such as manual work & 115 & 78 & $(68,59-76)$ & 32 & $(41,31-52)$ \\
\hline IADL & Q9 & Desire to go shopping when one wants to (includes both independently and with help) & 115 & 78 & $(68,59-76)$ & 43 & $(55,44-66)$ \\
\hline IADL & Q12 & Desire to cook, do laundry, and clean by oneself (includes both independently and with help) & 115 & 76 & $(66,57-74)$ & 23 & $(30,21-41)$ \\
\hline EL & Q13 & Desire to eat one's preferred meals (includes take-out and eating out) & 114 & 72 & $(63,54-71)$ & 56 & $(78,67-86)$ \\
\hline IADL & Q8 & $\begin{array}{l}\text { Desire to shave or put on makeup when one wants to (includes both independently and with } \\
\text { help) }\end{array}$ & 115 & 73 & $(63,54-72)$ & 44 & $(60,49-71)$ \\
\hline IADL & Q11 & Desire to control money at one's discretion & 115 & 63 & $(55,46-64)$ & 27 & $(43,31-55)$ \\
\hline EL & Q16 & Desire to talk more with staff & 115 & 57 & $(50,41-59)$ & 30 & $(53,40-65)$ \\
\hline EL & Q15 & Desire for more time to oneself and own space & 114 & 29 & $(25,18-34)$ & 13 & $(45,28-62)$ \\
\hline
\end{tabular}

Responses of residents to each item on the questionnaire are listed in descending order of percentage of residents who claimed that subjective need $B A D L$ basic activities of daily living, IADL instrumental activities of daily living, $E L$ environment and lifestyle, $E M$ emotion, $N 1$ the number of residents who had the need, N2 the number of care workers who understood the need (N1), $95 \%$ Cl $95 \%$ confidence interval

No significant difference was found in the proportions of residents with subjective needs by gender, age, cognitive function level, level of care needed, and independence in other ADL 
(age, gender, and years of experience) of care workers by the number of older residents assessed.

\section{Discussion}

In this study, we measured both resident subjective needs and care workers' understanding of resident needs, and found that while the residents had more subjective needs in the areas of BADL and EM than in the areas of IADL and EL, the care workers understood resident needs in IADL and EL areas to a lesser degree than needs in BADL and EM areas.

Most residents had common subjective needs in the areas of BADL and EM. Proportions of residents who expressed needs in the IADL and EL areas were low compared with those for BADL and EM areas. Of the 25 items, only Q15 ("Desire for more time to oneself and own space") in the EL area had a proportion lower than $50 \%$. For highly independent residents, such as those in this study who were able to express their intentions, care that prioritizes resident viewpoints (e.g., care that satisfies IADL and EL needs, such as those involving fulfillment of one's roles) will be needed in order to improve resident QOL. Previously, quality indicators focused on the older care process [19], medical management of older facility residents [20], and geriatric syndrome management [21] have been reported on resident care. In addition, six areas (home, room, social interaction, meal service, staff care, and resident involvement) have been reported as care satisfaction indicators [22]. Moreover, for older people with dementia in long-term care facilities, care providers must provide care based on the perspective of individualized care, focusing on personcentered care and understanding resident preferences $[23,24]$. In recent years, an intervention study was conducted to address quality improvement in long-term care [25].

The proportions of care workers who understood resident needs in BADL and EM areas were high, compared with IADL and EL areas. Because the items in BADL and EM areas reflect basic physiological needs [26], it is possible that care workers provide support for self-care and have emotional exchanges with residents on a daily basis. One concern, however, is that care workers might provide care assuming that older residents have uniform needs, even for those who have no such needs. As suggested by our results for items in IADL and EL areas, the proportion of care workers who understood resident needs is not necessarily high in these areas. Indeed, care workers were less likely to understand subjective IADL and EL needs, which varied widely by individual or preference, than BADL and EM needs, which most residents had in common. Resident subjective needs and values are key to assessing the quality of care [21], although this might be related to the manpower of facilities and care providing systems. It is necessary to provide care based on the autonomy and dignity of older individuals with a holistic outlook [27]. Previous studies have compared perceptions of care between providers and receivers [12, $13,28]$, and have revealed that the providers' perspective differs from that of receivers. Studies in the areas of nursing and care have found that care providers tend to overemphasize needs related to aspects of their own psyche $[12,13]$, and there were differences in responses regarding the needs of residents, care givers, and professionals [29]. In the present study, care workers' understanding of residents' needs varied by area (BADL, IADL, EL and EM).

The following three needs were expressed by more than $50 \%$ of residents, whereas less than $50 \%$ of care workers understood them: Q11 "keep money at hand" (43\%); Q12 "perform household chores themselves" (30 \%); and Q18 "need to play a role" (41\%). The former two were IADL needs and the latter, an EL need. These three items are all related to roles of residents and their demonstration of management ability, and thus linked to resident dignity. As human life activities and roles have meaning in each individual's life, clinical practitioners including care workers should promote and enable the kind of care that allows for the maintenance of role activities based on resident values and life history. Healthcare providers should be trained to probe the psychological needs of residents in daily care [30]. To this end, care workers need to explore ways to better understand resident subjective needs, and shift mindset from care provision limited inside the facility to one that focuses on resident preferences.

This study has some limitations. First, participants were not sampled randomly but selected via convenient sampling. Although each facility staff member selected participants (potentially causing selection bias), care worker understanding of each resident's subjective needs may have been insufficient. This underestimation of resident needs may have been even larger had we employed random sampling. Second, structured interviews were conducted by researchers, and not by usual care providers; therefore, resident subjective needs may have been excessively measured. However, this could be interpreted as having provided the opportunity for potential resident needs to rise to the surface, whereas residents might have refrained from expressing them out of consideration of the relationship with their regular care providers. Furthermore, as our participants were cognitively intact and were able to communicate verbally, application of the results to other older residents requires caution. Previous studies have reported the differences in needs of residents with dementia relative to those without dementia 
[31]. Finally, the present findings are based on data collected in 2008, and thus interpretation requires caution due to changes in the environment. However, as there has been almost no major policy change concerning long-term care facilities in Japan since 2008, the results of the present study are likely still valid.

\section{Conclusions}

Most aged care facility residents had common subjective needs in the areas of BADL and EM. Proportions of residents who expressed needs in the areas of IADL and EL were somewhat low relative to those with needs in BADL and EM, although more than half of the residents had needs in these areas. This may explain why care workers were likely to understand resident needs less in IADL and $\mathrm{EL}$ areas than in BADL and EM areas. It will be necessary for care workers to set care goals based on an understanding of resident subjective needs, and plan policies for care provision accordingly.

\section{Additional files}

Additional file 1. Translated version for older residents (original questionnaire was provided in Japanese).

Additional file 2. Translated version for staff (original questionnaire was provided in Japanese).

\section{Abbreviations}

QOL: quality of life; BADL: basic activities of daily living; IADL: instrumental activities of daily living; EL: environment and lifestyle; EM: emotion; ADL: activities of daily living.

\section{Authors' contributions}

TO, TH, and TN designed the study protocol and carried out data analysis; TO drafted the manuscript; $\mathrm{Tl}, \mathrm{TH}$, and TN supported the drafting of the manuscript and data analysis; and TN conceived and supervised the study. All authors read and approved the final manuscript.

\section{Author details}

${ }^{1}$ Department of Health Informatics, Kyoto University School of Public Health, Yoshida Konoe-cho, Sakyo-ku, Kyoto 606-8501, Japan. ${ }^{2}$ Division of Occupational Therapy, Faculty of Care and Rehabilitation, Seijoh University, 2-172, Fukinodai, Tokai City 476-8588, Japan. ${ }^{3}$ Division of Health Services Research, Center for Cancer Control and Information Services, National Cancer Center, 5-1-1, Tsukiji, Chuo-ku, Tokyo 104-0045, Japan. ${ }^{4}$ Tokyo Metropolitan Institute of Gerontology, 35-2 Sakae-cho, Itabashi-ku, Tokyo 173-0015, Japan.

\section{Acknowledgements}

This work, including the development of the questionnaire [10], was supported by a Grant-in-Aid (2007) from the Welfare and Medical Service Agency and was performed by the non-profit organization Life-Designing. TO, TH, and TN were commissioned as researchers of Life-Designing and received honoraria. The questionnaire used in this study was based on our previous study [11], which was performed by a non-profit organization, Association of Living for Ideal Care Enhanced (ALICE). It was partially funded by a Grant-inAid (2006) from the Welfare and Medical Service Agency. TO, TH, and TN were commissioned as researchers of ALICE and received honoraria.

\section{Competing interests}

TO and TN have received honoraria for consultations regarding testing the reliability and validity of the Modified Barthel Index from Asahi Kasei Pharma
Corporation (2013-2014), which had neither a direct nor indirect relationship with the work reported in the present manuscript. There are no other potential competing interests to report.

Received: 15 May 2015 Accepted: 11 January 2016

Published online: 28 January 2016

\section{References}

1. Tulchinsky TH, Varavikova EA. The new public health. Burlington: Elsevier Academic Press; 2009

2. United Nations Department of Economic and Social Affairs, Population Division: World Population Ageing 2013. http://www.un.org/en/development/desa/population/publications/pdf/ageing/WorldPopulationAgeing2013.pdf (2013). Accessed 3 March 2015.

3. Muramatsu N, Akiyama H. Japan: super-Aging Society Preparing for the Future. Gerontologist. 2011;51:425-32.

4. Ikegami N. Public long-term care insurance in Japan. JAMA. 1997;278:1310-4

5. Cabinet Office, Government of Japan. Annual Report on the Aging Society (Japanese language only). http://www8.cao.go.jp/kourei/ whitepaper/w-2014/zenbun/pdf/2s2s_2.pdf. Accessed 26 March 2015.

6. Wunderlich GS, Kohler PO, editors. Improving the Quality of Long-Term Care. Washington, DC: National Academy Press; 2001.

7. Kane RL. The Long and the Short of Long-Term Care. In: Cassel CK, Leipzig RM, Cohen HJ, Larson EB, Meier DE, editors. Geriatric Medicine. 4th ed. New York: Springer; 2003. p. 99-110.

8. Slade M. Needs assessment: involvement of staff and users will help to meet needs. Br J Psychiatry. 1994;165:293-6.

9. Crome P, Phillipson C. Assessment of need. Age Ageing. 2000;29:479-80.

10. Ohura T, Higashi T, Ishizaki T, Nakayama T. Testing validity and reliability of a newly developed instrument to assess the subjective needs of institutionalized elderly. Clin Gerontol. 2015;38:88-102.

11. Ohura T, Takada A, Nakayama T. Care goal setting and associated factors: semi-structured interviews with multidisciplinary care providers in facilities for elderly people. Int J Gerontol. 2014;8:12-7.

12. Löfmark A, Hannersjo S, Wikblad K. A summative evaluation of clinical competence: students' and nurses' perceptions of inpatients'individual physical and Emotion needs. J Adv Nurs. 1999;29:942-9.

13. Okamoto H, Okada S. Differences in subject needs between nursing home residents' and residential care professional's perspectives. Nippon Koshu Eisei Zasshi. 2002;49:911-21 (in Japanese).

14. Folstein MF, Folstein SE, McHugh PR. "Mini-mental state". A practical method for grading the cognitive state of patients for the clinician. $J$ Psychiatr Res. 1975;12:189-98.

15. Shah S, Vanclay F, Cooper B. Improving the sensitivity of the Barthel Index for stroke rehabilitation. J Clin Epidemiol. 1989:42:703-9.

16. Newcombe RG, Altman DG. Proportions and their differences. In: Altman DG, Machin D, Bryant TN, Gardner MJ, editors. Statistics with confidence. 2nd ed. London: British Library; 2000. p. 45-56.

17. Norman GR, Streiner DL. Biostatistics: The bare essentials. 3rd ed. Ontario: BC Decker, Inc; 2008.

18. IBM Corp. IBM SPSS Statistics for Windows, Version 20.0. Armonk: IBM Corp. 2011.

19. Saliba D, Schnelle JF. Indicators of the quality of nursing home residential care. J Am Geriatr Soc. 2002:50:1421-30.

20. Saliba D, Solomon D, Rubenstein L, Young R, Schnelle J, Roth C, et al. Quality indicators for the management of medical conditions in nursing home residents. J Am Med Dir Assoc. 2004;5:297-309.

21. Saliba D, Solomon D, Rubenstein L, Young R, Schnelle J, Roth C, et al. Feasibility of quality indicators for the management of geriatric syndromes in nursing home residents. J Am Med Dir Assoc. 2004;5:310-9.

22. Chou SC, Boldy DP, Lee AH. Measuring resident satisfaction in residential aged care. Gerontologist. 2001;41:623-31.

23. Kontos PC, Miller KL, Mitchell GJ. Neglecting the importance of the decision making and care regimes of personal support workers: a critique of standardization of care planning through the RAI/MDS. Gerontologist. 2010;50:352-62 
24. Janes N, Sidani S, Cott C, Rappolt S. Figuring it out in the moment: a theory of unregulated care providers' knowledge utilization in dementia care settings. Worldviews Evid Based Nurs. 2008;5:13-24.

25. Cranley LA, Norton PG, Cummings GG, Barnard D, Batra-Garga N, Estabrooks CA. Identifying resident care areas for a quality improvement intervention in long-term care: a collaborative approach. BMC Geriatr. 2012;25(12):59.

26. Maslow AH. Revised by Frager R, Fadiman J, McReynolds C, Cox R. Motivation and Personality. 3rd ed. New York:Longman; 1987.

27. Oliver D. Ethical and legal issues. In: Gosney M, Harris T, editors. Managing older people in primary care: a practical guide. New York: Oxford University Press; 2009. p. 301-16.

28. Rothwell PM, McDwell Z, Wong CK, Dorman PJ. Doctors and patients don't agree: cross sectional study of patients' and doctors' perceptions and assessments of disability in multiple sclerosis. Br Med J. 1997;314:1580-3.

29. Walters K, Iliffe S, Tai SS, Orrell M. Assessing needs from patient, carer and professional perspectives: the Camberwell Assessment of need for Elderly people in primary care. Age Ageing. 2000;29:505-10.

30. Custers AF, Cillessen AH, Westerhof GJ, Kuin Y, Riksen-Walraven JM. Need fulfillment, need importance, and depressive symptoms of residents over the first 8 months of living in a nursing home. Int Psychogeriatr. 2014:26:1161-70.

31. van der Ploeg ES, Bax D, Boorsma M, Nijpels G, van Hout HP. A crosssectional study to compare care needs of individuals with and without dementia in residential homes in the Netherlands. BMC Geriatr. 2013;24(13):51.
Submit your next manuscript to BioMed Central and we will help you at every step:

- We accept pre-submission inquiries

- Our selector tool helps you to find the most relevant journal

- We provide round the clock customer support

- Convenient online submission

- Thorough peer review

- Inclusion in PubMed and all major indexing services

- Maximum visibility for your research

Submit your manuscript at www.biomedcentral.com/submit
() Biomed Central 